\title{
Recognizing the blue emission in artificial aurora
}

\author{
H. Holma (1), K.U. Kaila (1), M.J. Kosch $(2,3,4)$ and M.T. Rietveld (5)
}

(1) Department of Physical Sciences, University of Oulu, Finland, (2) Air Force Research Laboratory, Hanscom AFB, Boston, USA, (3) On leave from Dept. Communication Systems, Lancaster University, UK, (4) Honorary Research Fellow, University of Kwazulu-Natal, Durban, South Africa (5) EISCAT Scientific Association, Ramfjordmoen, Norway.

\section{Abstract}

On $12^{\text {th }}$ November 2001, during an EISCAT UK/GE artificial aurora campaign, the optical group from the University of Oulu performed optical measurements at the EISCAT site in Ramfjordmoen, including the first measurement of blue emissions in artificial aurora at high latitudes. Optical instruments, including a photometer, a real speed TV camera and a digital camera, were monitoring the emissions. The emissions that the photometer was designed to mesure were $557.7 \mathrm{~nm}(\mathrm{OI}), 630.0 \mathrm{~nm}$ (OI) and $427.8 \mathrm{~nm}\left(\mathrm{~N}_{2}{ }^{+}\right)$. The energy thresholds of these emissions are approximately $2 \mathrm{eV}, 4 \mathrm{eV}$ and $19 \mathrm{eV}$, respectively.

In the natural aurora the blue emission at around $427.8 \mathrm{~nm}$ is always dominated by the $\mathrm{N}_{2}{ }^{+} 1 \mathrm{NG}(0,1)$ band. However, there are two weak emission bands lying under this strong emission, namely, the $\mathrm{N}_{2}$ $\mathrm{VK}(4,15)$ (threshold energy $6 \mathrm{eV}$ ) and $\mathrm{N}_{2} 2 \mathrm{P}(1,5)$ (threshold $11 \mathrm{eV}$ ). These excitation energies are lower than the energy needed to excite $\mathrm{N}_{2}{ }^{+} 1 \mathrm{NG}(0,1)$ level and therefore could have a stronger intensity compared with $\mathrm{N}_{2}{ }^{+} 1 \mathrm{NG}(0,1)$ in the spectrum of artificial aurora than in natural aurora.

The auroral photometer of the University of Oulu has been designed for investigating natural aurora. The photometer was equipped with two channels measuring different wavelength bands around 427.8 $\mathrm{nm}$. These channels were intended to be used to determine rotational temperature from the ratio of the intensities through the channels. However, here we estimate the intensities of the three overlapping emission bands instead.

\section{Introduction}

Artificially induced optical emissions by heating ionospheric electrons with powerful radio waves succeeded for the first time in 1970's at mid-latitudes (Sipler and Biondi, 1972; Gordon and Carlson, 1974; Haslett et al, 1974; Adeishvili et al., 1978). That was followed by several attempts at high latitudes by the EISCAT Heating facility near Tromso in Norway (Hendriksen et al., 1984; Stubbe et al. 1982). However, there was no convincing success until 1999 (Brändström et al., 1999; Kosch et al., 2000; Pedersen and Carlson, 2001) when atomic oxygen $\mathrm{O}^{1} \mathrm{D}$ (630.0 nm auroral red emission line) and $\mathrm{O}^{1} \mathrm{~S}$ (557.7 $\mathrm{nm}$ auroral green emission line) were detected. Since then there have been several successful measurement campaigns to produce artificial aurora using intense radio waves (e.g. Kosch et al., 2002; Rietveld et al., 2003).

During the November 2001 campaign (Kosch et al., 2004) at EISCAT, the blue emission was also observed for the first time. Initially, this was interpreted as $427.8 \mathrm{~nm}, \mathrm{~N}_{2}{ }^{+} 1 \mathrm{NG}(0,1)$ as expected for natural aurora. The oxygen $\mathrm{O}^{1} \mathrm{D}$ and $\mathrm{O}^{1} \mathrm{~S}$ states are excited by relatively low energy electrons $(1.96 \mathrm{eV}$ and $4.17 \mathrm{eV}$, respectively) (Vallance Jones 1974) and they are expected to be seen in the spectrum of 
artificial aurora (Haslett et al. 1974). The $\mathrm{N}_{2}{ }^{+} 1 \mathrm{NG}$ blue emission needs an excitation energy of $18.6 \mathrm{eV}$ (Lofthus and Krupenie,1977; Itikawa et al., 1986) making it difficult to understand how considerable amounts of nitrogen molecules could be excited to this state.

Instrumentation and experiment

The heating experiment was performed at the EISCAT site (69.58 N, 19.22 E) near Tromso in Norway. The experiment was part of a UK/GE EISCAT measurement campaign, which had as an objective to produce artificially induced auroral emissions using powerful radio waves to input energy into the ionosphere. The radio wave was transmitted in O-mode from the EISCAT site using the Heating facility. Different cycles and antenna directions were used (Kosch et al., 2004) but in this paper only the 2 min on -2 min off cycle is investigated. The transmitter antenna was pointed toward $9^{\circ}$ south of zenith. The effective radiated power was $550 \mathrm{MW}$ and the frequency was $5.423 \mathrm{MHz}$.

The ionospheric background conditions were monitored using a digital ionosonde and the EISCAT UHF radar (Ashrafi et al., 2004). The Finnish optical instrumentation at the EISCAT site, as well as a supporting station at Kilpisjärvi (69.02 N, 20.86 E), consisted of an auroral photometer, a digital auroral camera. At the EISCAT site also an image intensified real time camera for VHS video recordings was used.

The photometer at the EISCAT site had five channels for different wavelengths. Two of the channels were reserved for the nitrogen blue emission and the remaining three were $630.0 \mathrm{~nm}, 557.7 \mathrm{~nm}$ and $486.1 \mathrm{~nm}$ (proton precipitation). The photometer specifications are shown in Table 1. The photometer was scanning across a predetermined angle interval (about 50 to 90 degrees elevation angle south) around the heated volume, but during the time of interest it was stopped, pointing directly at the luminous area. The integration time was $0.4 \mathrm{~s}$ and the background was measured every 32 minutes.

Table 1. The photometer parameters. Channels 3b and 4b are created from channels 3a and 4a by tilting interference filters during the background measurement. P-peak, background, R-peak and R-tail for the blue channels refer to the filter positions shown in figure 3.

\begin{tabular}{|c|l|c|c|c|}
\hline Channel & \multicolumn{1}{|c|}{ Name } & Wavelength (nm) & FWHM (nm) & FOV ( ${ }^{\mathbf{o}}$ \\
\hline 1 & Proton & 486.1 & 1.26 & 2 \\
\hline 2 & Red & 630.0 & 1.58 & 0.6 \\
\hline 3a & Blue, P-peak & 427.8 & 1.24 & 0.6 \\
\hline 3b & Blue, background & 429.2 & 1.21 & 0.6 \\
\hline 4a & Blue, R-peak & 427.1 & 0.63 & 0.6 \\
\hline 4b & Blue, R-tail & 425.7 & 0.88 & 0.6 \\
\hline 5 & Green & 557.7 & 1.18 & 0.6 \\
\hline
\end{tabular}




\section{Measurements}

The photometer was designed for determining rotational temperatures from the fine structure of the $\mathrm{N}_{2}{ }^{+}$ $1 \mathrm{NG}(0,1)$ band. This is a molecular emission band, where the rotational emission lines result from transitions from different rotational energy states. The initial electronic-vibrational state is $\mathrm{N}_{2}{ }^{+} \mathrm{B}^{2} \Sigma_{\mathrm{u}}{ }^{+}$ $(v=0)$ and the final state is $\mathrm{N}_{2}{ }^{+} \mathrm{X}^{1} \Sigma_{\mathrm{g}}{ }^{+}(\mathrm{v}=1)$. The populations of the rotational states follow the rule $\mathrm{N}(\mathrm{K}$ ' $)=\mathrm{N}_{0} \exp \left(\mathrm{K}^{\prime \prime}(\mathrm{K}\right.$ ' +1$\left.) / \mathrm{kT}\right)$, where $\mathrm{N}_{0}$ is total number of $\mathrm{N}_{2}{ }^{+}$molecules, $\mathrm{K}$ ' is the rotational number of the upper level, $\mathrm{k}$ is Bolzmann's constant and $\mathrm{T}$ is temperature of the ambient neutral gas in thermal equilibrium (Vallance Jones, 1974). The neutral gas can be expected to keep its thermal characteristic condition for several minutes while the plasma is heated by the radio waves under the ionospheric conditions prevailing at $230 \mathrm{~km}$ (Gurevich, 1978).

The $\mathrm{N}_{2}$ population distribution changes with temperature. The shape of the resulting emission band is temperature dependent as well. This dependence has been used to determine the temperature of the emitting gas volume by recognizing the shape of the emission band from photometer data. For determining rotational temperature with a photometer more than one channel is needed. In this case there were two channels (see figure 2), with one band on the R-branch and the other on the P-branch of the $\mathrm{N}_{2}{ }^{+} 1 \mathrm{NG}(0,1)$ band. As the shape of the band changes with the temperature of the emitting gas, it is possible to interpret the ratio of the intensities of these two channels as the temperature of the emitting gas (Hunten et al., 1963). In this case the ratio of R-Peak/P-Peak intensities would vary between 0.27 and 0.33 when temperature goes from 700 to $1500 \mathrm{~K}$, as shown in fig. 1. 


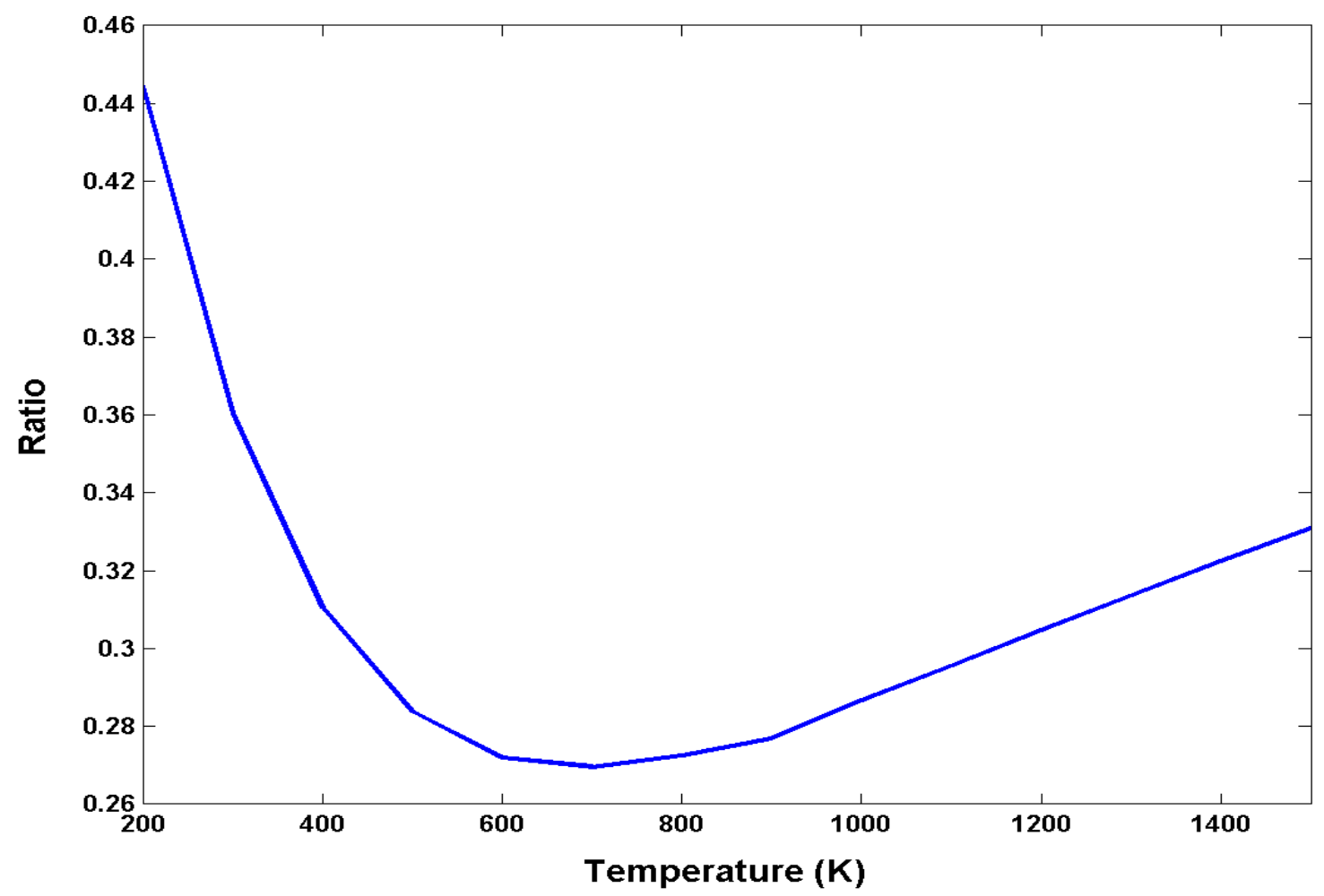

Figure 1. The calculated intensity ratio R-peak/P-peak for $\mathrm{N}_{2}{ }^{+} 1 \mathrm{NG}(0,1)$ emission band as a function of neutral gas temperature.

The artificially stimulated blue emission was detected at various times during the evening of 12 Nov 2001 from Tromso, for the first time ever at high latitudes. The nitrogen emission was especially prominent from 16:30 to 17:00 UT (see Fig. 2), when the photometer scan was stopped with the instrument pointing directly toward the emission region. This time interval was chosen for the present study. During the time of interest there are eight full heating cycles clearly visible in the photometer data from Tromso, as shown in figure 2. All the photometer channels show a clear signal (except for $481.6 \mathrm{~nm}$ ). The numbers from 1 to 8 denote the cycles. The last cycle (number 9 ) is only partly resolved. 

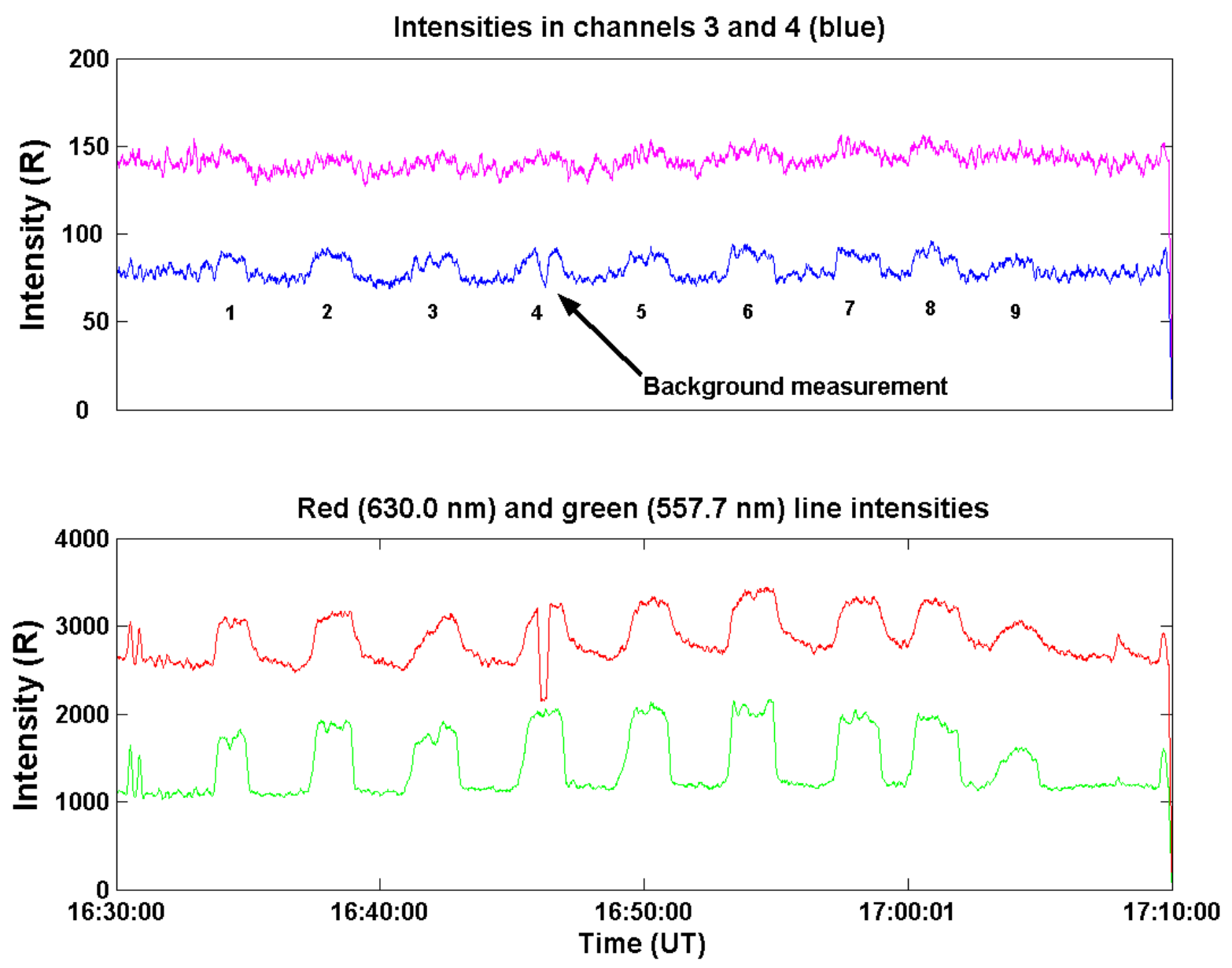

Figure 2. The top panel shows calibrated optical intensities for the blue emissions. The upper and lower curves show photometer channels 3a (P-Peak) and 4a (R-Peak), respectively. The bottom panel shows calibrated optical intensities for 630 (upper curve) and $557.7 \mathrm{~nm}$ (lower curve). The heater on periods have been denoted with numbers from 1 to 9 . The arrow shows the time at which the background measurement was taken. The integration time for the measurements was 0.4 seconds. The data have been averaged over 20 data points for the plot.

The cycles have been handled individually so that for both channels the intensity has been integrated throughout the whole on-phase of each cycle to get the signal and throughout the whole off-phase to get the background. The integrated intensities through the R-filter have been divided by the integrated intensities through the P-filter to get the background-subtracted intensity ratios. The photometer intensities and their ratios are presented in table 2.

Table 2. Background-subtracted calibrated intensities (Rayleighs) through the P-peak and R-peak channels and ratios of these intensities during heating-on periods. 


\begin{tabular}{|c|c|c|c|}
\hline Period number & P-Peak & R-Peak & Ratio \\
\hline 1 & 7.0 & 5.3 & 0.74 \\
\hline 2 & 11.9 & 5.8 & 0.48 \\
\hline 3 & 7.5 & 4.7 & 0.63 \\
\hline 4 & 6.6 & 3.7 & 0.57 \\
\hline 5 & 11.2 & 6.6 & 0.59 \\
\hline 6 & 10.6 & 6.4 & 0.60 \\
\hline 7 & 9.2 & 6.6 & 0.72 \\
\hline 8 & 11.2 & 6.6 & 0.59 \\
\hline 9 & 5.5 & 2.8 & 0.51 \\
\hline
\end{tabular}

Results

Table 2 shows that the intensities vary from 5.5 to 11.9 Rayleighs in the P-peak channel and from 2.8 to 6.6 Rayleighs in the R-peak channel with averages of 9.0 and 5.4 Rayleighs, respectively. For the background measurement, the P-peak filter shifts to the background position at a longer wavelength (channel 3b in table 1) and the R-peak filter to the R-tail position at a shorter wavelength (channel 4b in table 1) by (un)tilting the relevant filter (Kaila, 2003). This means that during the background measurement the photometer is using channels $3 \mathrm{~b}$ and $4 \mathrm{~b}$ instead of channels $3 \mathrm{a}$ and $4 \mathrm{a}$. This measurement is intended to measure background light level in normal auroral studies. Now channel $3 \mathrm{~b}$ (filter P-background) would be measuring part of the $\mathrm{N}_{2} \mathrm{VK}(4,15)$ emission band (see fig. 3).

During the background measurement in heating period four (seen in figure 2 as a sudden intensity reduction in the middle of the period 4, marked with an arrow), the intensity in the R-tail channel is 75 $\%$ of the R-peak intensity. The intensity in the background channel of the P-peak is effectively equal to the background level. Comparing the emission ratios in table 2 to calculated values shown in fig. 1, which range from 0.27 at $600 \mathrm{~K}$ to 0.45 at $200 \mathrm{~K}$ at the lower temperatures and to 0.32 at $1400 \mathrm{~K}$ at the higher temperatures, the ratio never reaches 0.5 even at unrealistically high temperatures. It is obvious that there is something not in order with the $\mathrm{N}_{2}{ }^{+} 1 \mathrm{NG}(0,1)$ emission. The measured ratios are not even on the scale of the expected temperature range. A ratio of $0.27-0.33$ is expected around the probable neutral gas temperatures of 700-1500 K. Hence, it is not possible to determine temperature from this data. This means that the blue emission cannot originate purely from the $\mathrm{N}_{2}{ }^{+} 1 \mathrm{NG}(0,1)$ band!

The most likely explanation for the unexpected intensity ratio R-peak/P-peak would be the existence of other atomic or molecular emissions in this exceptional condition, i.e. for ionospheric heating. There are two other emissions in the same wavelength region as the $\mathrm{N}_{2}{ }^{+} 1 \mathrm{NG}(0,1)$ band. They are the molecular nitrogen bands $\mathrm{N}_{2} \mathrm{VK}(4,15)$ and $\mathrm{N}_{2} 2 \mathrm{P}(1,5)$ having threshold energies of $\sim 6 \mathrm{eV}$ and $\sim 11 \mathrm{eV}$, respectively. Although these energies are high compared to the atomic oxygen excitation energies, artificial optical emissions at $777.4 \mathrm{~nm}$ (Djuth et al., 2004), corresponding to 11 eV, and $844.6 \mathrm{~nm}$ 
(Gustavsson et al., 2004) corresponding to $\sim 9 \mathrm{eV}$ have been reported. Hence, it is entirely possible the $\mathrm{N}_{2} \mathrm{VK}(4,15)$ and $\mathrm{N}_{2} 2 \mathrm{P}(1,5)$ bands can be stimulated. The three $\mathrm{N}_{2}$ emission bands lie in the same wavelength region mixed together and are normally not resolved in photometer data. These are shown in fig. 3 along with the filter transmission curves for photometer channels 3 and 4 . In natural aurora the $\mathrm{N}_{2}{ }^{+} 1 \mathrm{NG}(0,1)$ emission dominates. If there were more photometer channels with narrow band filters measuring in the wavelength range of interest, it would be possible to estimate relative intensities of these overlaying nitrogen bands. Likewise, a spectrograph would be able to resolve the different contributions.

The available photometer data was used to estimate the intensities of the $\mathrm{N}_{2}{ }^{+} 1 \mathrm{NG}(0,1), \mathrm{N}_{2} \mathrm{VK}(4,15)$ and $\mathrm{N}_{2} 2 \mathrm{P}(1,5)$ bands using a reasonable estimate of the neutral gas temperature. The intensity ratios (R-Peak/P-Peak) as a function of temperature were calculated for all of these emission bands. The oxygen 557.7 and $630 \mathrm{~nm}$ emissions occur at a height of 215 - $235 \mathrm{~km}$ (Kosch et al., 2004), decreasing in altitude during each heater cycle. The atmospheric neutral temperature is close to $1100 \mathrm{~K}$ in this height range according to the MSIS model, which is consistent with the ion temperature measured by EISCAT. From the intensity ratio calculations we know that $1100 \mathrm{~K}$ corresponds to a ratio of 0.30 for $\mathrm{N}_{2}{ }^{+} 1 \mathrm{NG}(0,1), 1.00$ for $\mathrm{N}_{2} \mathrm{VK}(4,15)$ and 2.75 for $\mathrm{N}_{2} 2 \mathrm{P}(1,5)$. The measured intensity ratios can be reconstructed if the intensity of $\mathrm{N}_{2} 2 \mathrm{P}(1,5)$ is about $27 \%$ higher than the intensity of $\mathrm{N}_{2}{ }^{+} 1 \mathrm{NG}(0,1)$ while the $\mathrm{N}_{2} \mathrm{VK}(4,15)$ intensity is close to zero. We have estimated the photometer measurement error from the background measurement taken in cycle 4 to be $1.5 \mathrm{R}$. Thus the intensity of $\mathrm{N}_{2} \mathrm{VK}(4,15)$ cannot be more than this.

If we assume the maximum $\mathrm{N}_{2} \mathrm{VK}(4,15)$ through the P-peak filter is $1.5 \mathrm{R}$, which means the intensity is $2.3 \mathrm{R}$ for whole band, we calculate the intensities of other two bands to be $13.5 \mathrm{R}$ for the $\mathrm{N}_{2} 2 \mathrm{P}(1,5)$ and $14.8 \mathrm{R}$ for the $\mathrm{N}_{2}{ }^{+} 1 \mathrm{NG}(0,1)$ emission band. These results are shown in Table 3.

Table 3. Estimates for the intensities of the three emission bands in Rayleighs.

\begin{tabular}{|l|c|c|}
\hline \multicolumn{1}{|c|}{ Emission band } & $\begin{array}{c}\text { Intensities when } \mathrm{N}_{2} \text { VK(4,15) is } \\
\text { assumed to be faint }\end{array}$ & $\begin{array}{c}\text { Intensities when } \mathrm{N}_{2} \text { VK(4,15) is } \\
\text { assumed to be } 2.3 R\end{array}$ \\
\hline $\mathrm{N}_{2}{ }^{+} 1 \mathrm{NG}(0,1)$ & $17.2 \mathrm{R}$ & $14.8 \mathrm{R}$ \\
\hline $\mathrm{N}_{2} 2 \mathrm{P}(1,5)$ & $22.0 \mathrm{R}$ & $13.5 \mathrm{R}$ \\
\hline $\mathrm{N}_{2} \mathrm{VK}(4,15)$ & $0 \mathrm{R}$ & $2.3 \mathrm{R}$ \\
\hline
\end{tabular}




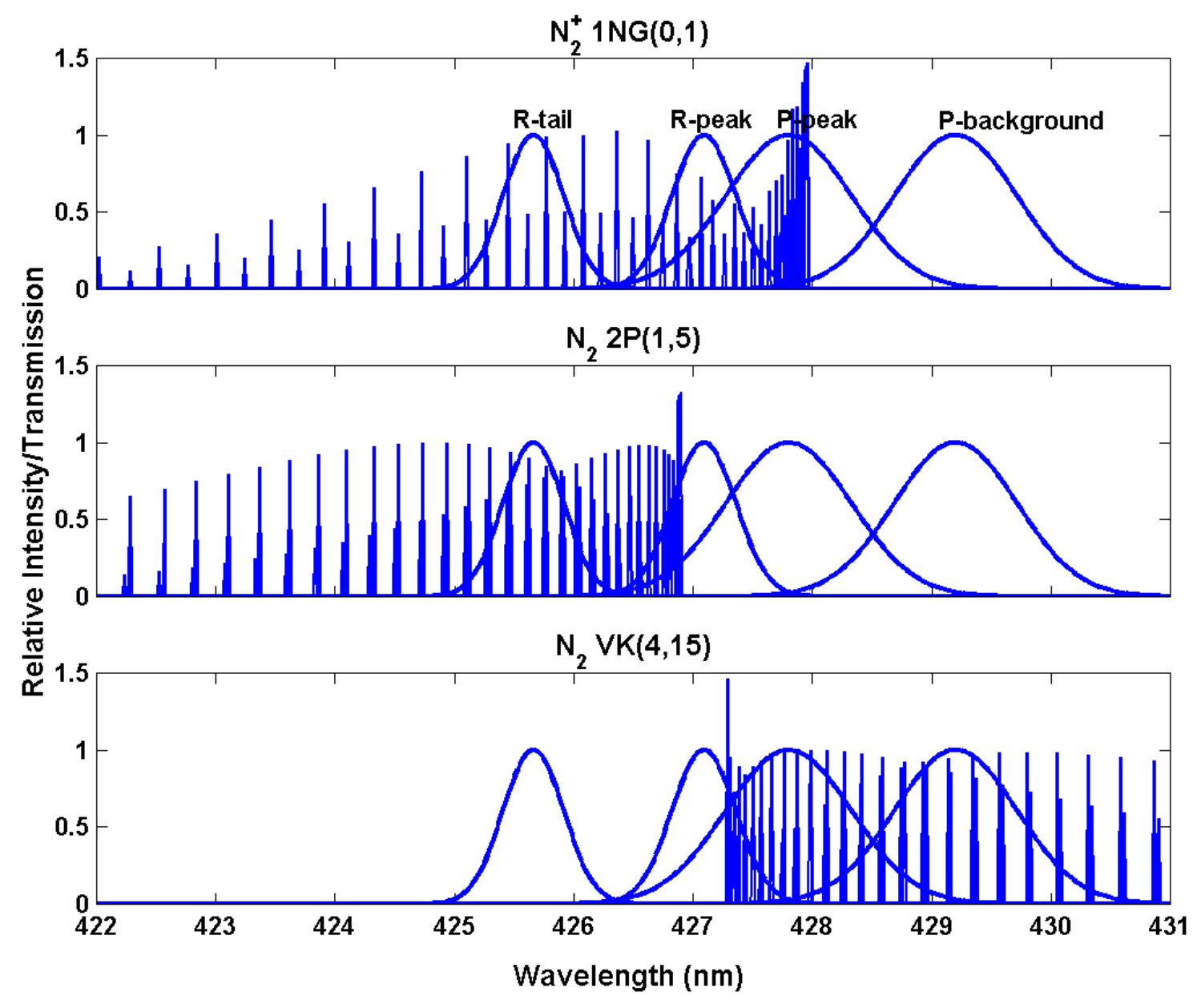

Figure 3. The three rotational emission bands $\mathrm{N}_{2}{ }^{+} 1 \mathrm{NG}(0,1)$, top panel, $\mathrm{N}_{2} 2 \mathrm{P}(1,5)$, middle panel, and $\mathrm{N}_{2} \mathrm{VK}(4,15)$, bottom panel, together with the filter transmission curves. The filters are named according to the position of the peaks of their transmission curves compared to the 1NG-band. The filter curves are the same in all panels, but they have been named in the uppermost panel only.

\section{Conclusions and discussion}

The initial aim of the analysis was to determine height of the blue emission in the artificial aurora by using the rotational temperature method. Unfortunately, the blue emission can not be triangulated because there is data from just one station on 12/11/2001 for these wavelengths. However, the intensity ratios $\mathrm{R}$-peak/P-peak were unrealistically high. They were first thought to represent an extremely high temperature of the emitting neutral gas volume, but the measured intensity ratios are in fact not realistic at all for any temperature. In addition, Ashrafi et al. (2004) have estimated the electron temperature maximum to be $<6000 \mathrm{~K}$ during this experiment, thereby limiting the maximum possible neutral gas temperature.

We have ruled out other possible explanations such as instrumentation malfunction, errors in calibration or errors in the emission band calculations. Using triangulation, the altitude of the green and 
red line oxygen emissions were estimated to be $210-215 \mathrm{~km}$ by one of us (K. Kaila), consistent with the steady state altitude estimate by Kosch et al. (2004). The radio wave reflection height estimated from dynasonde and EISCAT data is $220-235 \mathrm{~km}$. (Kosch et al. 2004). These heights do not give the altitude of the blue emission, but it is reasonable to assume that all the emissions arise quite close to each other. Thus we can also rule out resonant scattering caused by sunlit, as the sun's shadow was already at a height of $290 \mathrm{~km}$ at 16:30 UT.

A reasonable candidate for interfering with the normal processes in the heated gas volume is resonance in the transfer of momentum from the electrons to the molecules. This may happen for low energy electrons in inelastic collisions with the $\mathrm{N}_{2}$ molecules, resulting in an excess population of the lowest rotational states. This effect may be visible when the bombarding electrons have energies close to the threshold energy, as in the case of artificial aurora. However, the error in the temperature measurement should be of the order of $50 \mathrm{~K}$ at a temperature of $300 \mathrm{~K}$ (Culp and Stair, 1967) measured using a spectrometer. This effect is too small to explain the observed results.

We conclude that the blue emission is dominated by $\mathrm{N}_{2}{ }^{+} 1 \mathrm{NG}(0,1)$, which has an excitation threshold of $\sim 19 \mathrm{eV}$ and $\mathrm{N}_{2} 2 \mathrm{P}(1,5)$, with an excitation threshold of $\sim 11 \mathrm{eV}$. The blue emission probably also includes a small contribution from $\mathrm{N}_{2} \mathrm{VK}(4,15)$, with an excitation threshold of $\sim 6 \mathrm{eV}$. The presence of the blue emission clearly indicates the non-thermal nature of the heated electron population. This strongly suggests that non-linear electron acceleration processes are present in the turbulent plasma, consistent with the finding of Ashrafi et al. (2004) and Kosch et al. (2004) using EISCAT radar data.

Acknowledgements:

The EISCAT facilities are funded by research organisations from Finland, France, Germany, Japan, Norway, Sweden and the United Kingdom.

References:

Adeishvili, T.G., A.V. Gurevich, S.B. Lyakhov, G.G. Managadze, G.M. Milikh and I.S. Shluyuger, Ionospheric emission casued by an intense radio wave, Sov. J. Plasma Phys., 4, 721, 1978.

Ashrafi, M., M. J. Kosch and F. Honary, Heater-induced altitude descent of the EISCAT UHF ion line enhancements: Observations and modelling, submitted to this issue of Adv. Space Res., 2004.

Brändström, B.U.E., T.B. Leyser, A. Steen, M.T. Rietveld, B. Gustavsson, T. Aso and M. Ejiri, Unambiguous evidence of HF pump-enhanced airglow at auroral latitudes, Geophys. Res. Lett., 26, 3561-3564, 1999.

Culp, G., and A.T. Stair Jr., Journal de Chimie Physique, 64(1), 57-62, 1967.

Djuth, F.T., T. R. Pedersen, E. Gerken, C. Selcher, W.A. Bristow and M.J. Kosch, Ionospheric modification at twice the electron cyclotron frequency, submitted to Phys. Rev. Lett., 2004.

Gordon, W.E., and H.C. Carlson Jr., Arecibo heating experiments, Radio Sci., 9, 1041-1047, 1974. 
Gurevich, A.V., Nonlinear phenomena in the ionosphere, Springer-Verlag, New York, USA, 1978.

Gustavsson, B., T. Sergienko, M.J. Kosch, M.T. Rietveld, A. Steen, U. Brändström, T.B. Leyser, B. Isham, P. Gallop, T. Aso, M Ejiri, K. Kaila, J. Jussila and H. Holma, The electron distribution during HF pumping - a picture painted with all colours, submitted to Ann. Geophys., 2004.

Haslett, J.C. And L.R. Megill, A model of the enhanced airglow excited by RF-radiation, Radio Sci., 9, 1005-1019, 1974.

Hendriksen, K., W. Soffegren, B. Lybekk and A. Steen, Photometer and spectrometer search af the oxygen green and red lines during artificial heating in the auroral zone, Ann. Geophys., 2, 73-76, 1984. Hunten D.M., E.G. Rawson, and J.K. Walker, Rapid measurement of $\mathrm{N}_{2}{ }^{+}$rotational temperatures in aurora, Can. J. Phys., 41, 1963.

Itikawa, Y., Hayashi, M., Ichimura, A., Onda, K., Sakimoto, K., Takayanagi, K., Nakamura, M., Nishimura, H., and Takayanagi, T., Cross sections for collisions of electrons and photons with nitrogen molecules, J. Phys. Chem. Ref. Data, 15, 985-1010, 1986.

Kaila , K.U., Multichannel auroral photometer, Geophysica, 39(1-2), 75-90, 2003.

Kosch, M.J., M.T. Rietveld, A. Senior, I.W. McCrea, A.J. Kavanagh, B. Isham, Novel artificial optical annular structures in the high latitude ionosphere over EISCAT, Geophys. Rev. Lett., Vol. 31, L12805, doi:10.1029/2004GL019713, 2004.

Kosch, M.J., M.T. Rietveld, T. Hagfors and T.B. Leyser, High-latitude HF-induced airglow displaced equatorwards of the pump beam, Geophys. Res. Lett., 27, 2817-2820, 2000.

Lofthus, A. and P.H. Krupenie, The spectrum of molecular nitrogen, J. Phys. Chem. Ref. Data, 6, No 1, 1977.

Pedersen, T.R., and H.C. Carlson, First observations of HF heater-produced airglow at the High Frequency Active Auroral Research Program facility: Thermal excitation and spatial structuring, Radio Sci., 36, 1013-1026, 2001.

Rietveld, M.T., M.J. Kosch, N.F. Blagoveshchenskaya, et al., Ionospheric electron heating, optical emissions and striations induced by powerful HF radio waves at high latitudes: Aspect angle dependence, J. Geophys. Res., 108(A4), 1141, doi:10.1029/2002JA009543, 2003.

Sipler, D.P., and M.A. Biondi, Measurements of $\mathrm{O}\left({ }^{1} \mathrm{D}\right)$ quenching rates in the F region, J. Geophys. Res., 77, 6202-6212, 1972.

Stubbe, P., H. Kopka, H. Lauche, M.T. Rietveld, A. Brekke, O. Holt, T.B. Jones, T. Robinson, A. Hedberg, B Thide, B. Crochet and H.J. Lotz, Ionospheric modification experiments in northern Scandinavia, J. Atmos. Terr. Phys., 44, 1025-1041, 1982.

Vallance Jones, Aurora, D. Reidel, Hingham, Mass., USA, 1974. 